\title{
The Importance of Understanding the Nature of Science for Accepting Evolution
}

\author{
Tania Lombrozo • Anastasia Thanukos • \\ Michael Weisberg
}

Published online: 20 June 2008

(C) Springer Science + Business Media, LLC 2008

\begin{abstract}
Many students reject evolutionary theory, whether or not they adequately understand basic evolutionary concepts. We explore the hypothesis that accepting evolution is related to understanding the nature of science. In particular, students may be more likely to accept evolution if they understand that a scientific theory is provisional but reliable, that scientists employ diverse methods for testing scientific claims, and that relating data to theory can require inference and interpretation. In a study with university undergraduates, we find that accepting evolution is significantly correlated with understanding the nature of science, even when controlling for the effects of general interest in science and past science education. These results highlight the importance of understanding the nature of science for accepting evolution. We conclude with a discussion of key characteristics of science that challenge a simple portrayal of the scientific method and that we believe should be emphasized in classrooms.
\end{abstract}

Keywords Accepting evolution - Understanding evolution . Nature of science $\cdot$ Philosophy of science

T. Lombrozo $(\square)$

Department of Psychology, University of California, Berkeley, 3210 Tolman Hall,

Berkeley, CA 94720, USA

e-mail: lombrozo@berkeley.edu

A. Thanukos

Museum of Paleontology, University of California,

1101 Valley Life Sciences Building,

Berkeley, CA 94720, USA

\section{Weisberg}

Department of Philosophy, University of Pennsylvania,

433 Logan Hall,

Philadelphia, PA 19104, USA

\section{Introduction}

Fewer than $50 \%$ of Americans accept Darwin's theory of evolution by natural selection (Miller et al. 2006), a statistic considerably at odds with the overwhelming support for evolution in most industrialized nations and within the scientific community (Miller et al. 2006; AAAS 2006; NAS 2008a, b). Evolution informs practice and progress in areas from medicine and biotechnology to environmental policy and public health, which makes the widespread rejection of evolution a serious public concern.

What can be done in America's classrooms to promote the acceptance of evolution? A natural response is to focus exclusively on improving students' understanding of evolution and hope that acceptance will follow. But, while understanding evolution is a valuable end in itself, studies repeatedly find that understanding evolution is not reliably correlated with accepting evolution (e.g., Bishop and Anderson 1990; Lawson and Worsnop 1992; Demastes et al. 1995; Sinatra et al. 2003; Brem et al. 2003; Shtulman 2006). The implication is that improving students' understanding is not sufficient to impact acceptance. Furthermore, while there are social factors that do correlate with accepting evolution, such as religious affiliation and political views (Miller et al. 2006), it would arguably be inappropriate for teachers to set out to change such factors in the classroom.

An alternative approach is to focus on careful instruction about the nature of science. Perhaps what students and the public at large are missing is not just the content of evolutionary theory but an understanding of its scientific status and of the methods that have repeatedly supported its central claims. In particular, accepting evolution may require an appreciation of the fact that a scientific theory is reliable (not a mere guess) but also provisional (subject to 
ongoing revision). Furthermore, recognizing the overwhelming evidence for evolution may require an appreciation of the fact that evidence can come in many forms, result from diverse methods, and require inference and interpretation to bear on theories.

Although many states include "the nature of science" in their science standards, students often have robust misconceptions about the nature of science, and some science teachers share these misconceptions (e.g., Lederman 1992; Scharmann and Harris 1992; Carey and Smith 1993; Solomon et al. 1996; Dagher and BouJaoude 2005). For example, many students believe that theories can simply be "read off" from the world, that scientific claims can be definitively proved, and that theories have not yet achieved the privileged status of facts or laws. These misconceptions may be aggravated by teaching what textbooks usually call "the scientific method": a linear sequence of steps suggesting that scientists follow a single, fixed process to develop laboratory experiments that directly and definitively test hypotheses.

The last 50 years of historical and philosophical study of science have shown us that this formulaic, hypotheticodeductive portrayal of science is extremely impoverished (e.g., Kuhn 1962; Kitcher 1993; for an accessible introduction, see Godfrey-Smith 2003). Scientific practice is far more diverse and dynamic than the introductory chapters of most science textbooks would suggest. For example, the connection between theory and evidence in all of modern science is indirect, relying on many layers of intermediary theories and auxiliary hypotheses. In addition, there is no universal path for scientific discovery and testing. Communities of scientists, not individuals, are required to solve all but the simplest scientific problems, and there are multiple cross-cutting relationships between most scientific hypotheses and theories.

A sophisticated understanding of the nature of science may be especially critical for understanding and accepting evolution. Some sciences conform more closely to a simplified stereotype of scientific methods than do others: the lone scientist performing a critical laboratory experiment that will definitively prove one theory or another. When it comes to evolution, laboratory experiments provide only one source of data. Much of what we know about the mechanisms of evolution and the evolutionary "tree of life" was discovered through field observations, museum research, examinations of the fossil record, and molecular biology. These lines of evidence were collected and documented over many years, often by large teams of researchers. The aggregated results provide an evergrowing database of facts from which theorists can ask and answer questions about the course of evolution. At no single point in the process does a scientist formulate a hypothesis about the entirety of the phylogenetic tree, perform a specific test, then either accept or reject the hypothesis, in the manner suggested by simplistic pictures of scientific inquiry.

For these reasons and others, educators and researchers have advocated teaching a more realistic picture of the nature of science alongside evolution (e.g., Nickels et al. 1996; Dagher and BouJaoude 1997, 2005; Rudolph and Stewart 1998; NSTA 2000; Bybee 2001; Sinatra et al. 2003; Farber 2003; Scharmann et al. 2005; Lombrozo et al. 2006; NAS 2008a, b; Tattersall 2008; Gregory 2008). However, evidence for the efficacy of this approach has been sparse. Among science teachers, understanding the nature of science may be correlated with accepting evolution (Rutledge and Warden 2000; Trani 2004), and there is some suggestive evidence that learning about the nature of science can increase acceptance of evolution in teachers (Scharmann and Harris 1992) and in students (Verhey 2005). But, a great deal remains to be learned about the relationship between understanding the nature of science and accepting evolution and in particular whether an evolution curriculum that includes the nature of science increases acceptance.

In the current study, we examine the relationship between college undergraduates' understanding of the nature of science and their acceptance of evolution. In particular, we predict that understanding certain aspects of science, such as the role of testing and the nature of theories, will contribute to accepting evolution. If understanding the nature of science causally impacts the acceptance of evolution, then we should find a correlation between our measures for understanding the nature of science, on the one hand, and accepting evolution, on the other. We also examine other aspects of science, such as the role of the scientific community, and measure students' attitudes toward science, beliefs about the limits of science, past science education, and religiosity. Two of these additional measures, students' attitudes toward science and past science education, are especially critical for disentangling the possibility that understanding science causally contributes to accepting evolution from the alternative that both understanding science and accepting evolution have a common cause, such as a general tendency to endorse science.

\section{Materials and Methods}

Participants Ninety-six undergraduates (67\% women; mean age 20) from a large, public university on the West Coast of the USA participated in the study in exchange for course credit. Participants included psychology majors as well as students from a range of other departments. 
Materials The study consisted of an 18-page questionnaire divided into seven parts. In the first part, participants rated their agreement or disagreement with 60 statements about the nature of science on a five-point Likert scale $(1=$ "strongly disagree," $2=$ "disagree," $3=$ "neither agree nor disagree," 4="agree," 5="strongly agree"). The 60 items were further organized into 12 sets of five, with each set of five presented on a single page and addressing a single theme concerning the nature of science (see Table 1 for themes and sample items). Many of the themes and items were based on the Student Understanding of Science and Scientific Inquiry instrument (Liang et al. 2006), with additional items and themes added to target additional aspects of science and key misconceptions. The 12 themes were presented in 1 of 12 orders, conforming to a Latin square, and the five items within a theme were presented in one of two random orders. For each set of five items, two had a reverse valence from the rest so that endorsing the theme would involve a mix of "agree" and "disagree" responses.

In parts $2-5$ of the questionnaire, participants continued to evaluate Likert items clustered in sets of five around a theme. These themes concerned the limits of scientific inquiry (limits), attitudes towards science (attitude), acceptance of evolution (evolution acceptance), and religious belief (religiosity; see Table 2). The items corresponding to each theme were presented in one of two random orders, but the theme order was fixed across participants. Again,

Table 1 Nature of science themes with sample items and mean ratings for theme, followed by the standard deviation

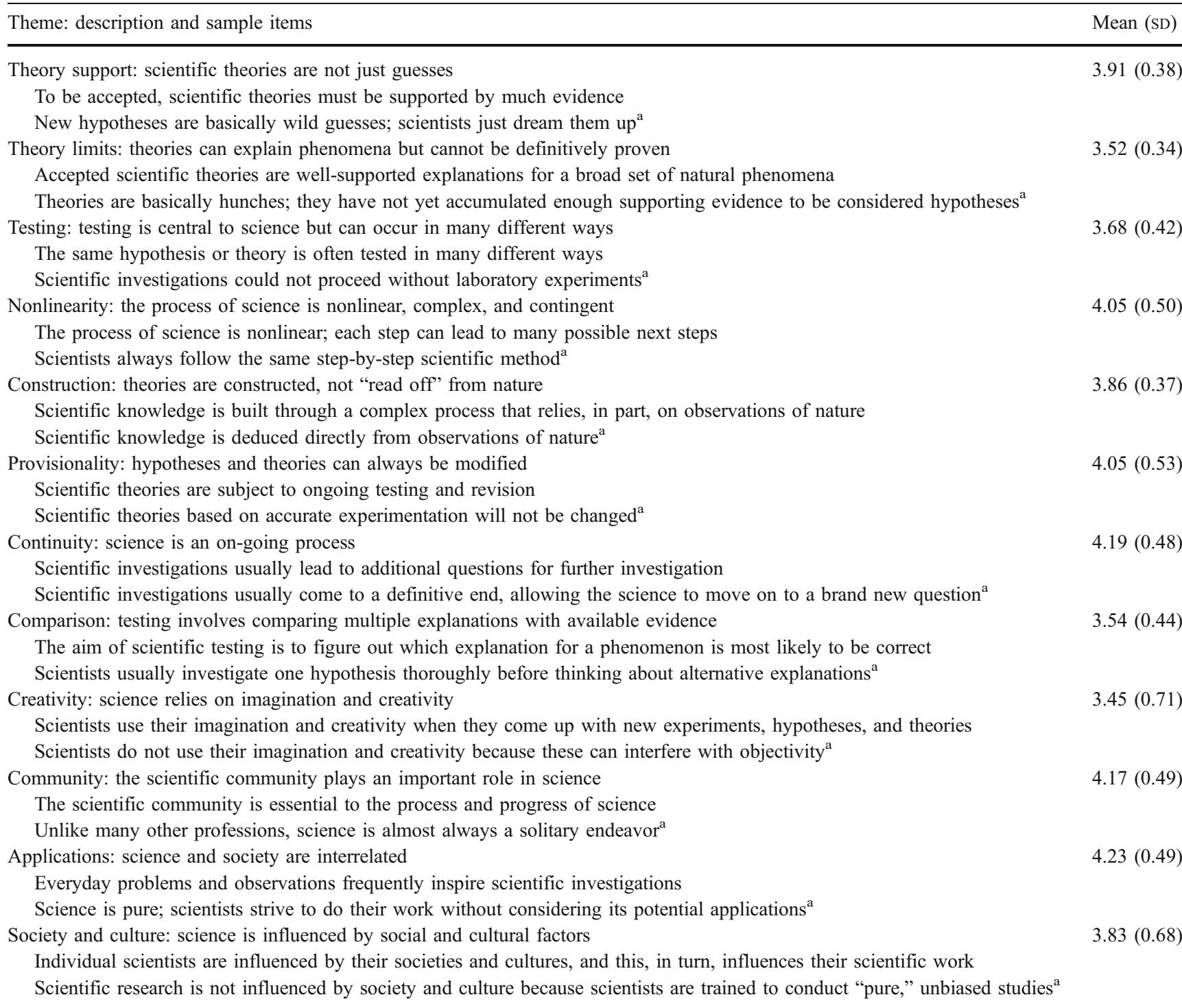

The rating scale ranged from 1 to 5 , with 1 indicating strong disagreement and 5 indicating strong agreement.

${ }^{a}$ Indicates items that were reverse coded to generate the mean for the theme. 
Table 2 Mean values for limits of science, attitude toward science, acceptance of evolution, and religiosity items

\begin{tabular}{|c|c|}
\hline Theme and items & Mean (SD) \\
\hline Limits of science & $3.64(0.61)$ \\
\hline Science cannot address the existence of supernatural entities or investigate supernatural mechanisms & $3.27(1.14)$ \\
\hline Science can help inform decisions related to morality but cannot directly make moral judgments about what is good and bad & $3.56(0.92)$ \\
\hline Science and technology cannot solve all human problems & $4.16(0.99)$ \\
\hline Science could prove the existence of supernatural beings like God ${ }^{\mathrm{a}}$ & $2.35(1.08)$ \\
\hline Science could disprove the existence of supernatural beings like God $^{\mathrm{a}}$ & $2.42(1.02)$ \\
\hline Attitude toward science & $3.91(0.64)$ \\
\hline I am generally more interested in science than my peers are & $3.41(0.99)$ \\
\hline I am interested in pursuing a career related to science, technology, engineering, or mathematics & $3.66(1.37)$ \\
\hline I personally think that science is extremely valuable for society & $4.32(0.62)$ \\
\hline I think that science often has more negative repercussions for society than positive repercussions $\mathrm{s}^{\mathrm{a}}$ & $1.97(0.80)$ \\
\hline I personally think that science is boring ${ }^{\mathrm{a}}$ & $1.88(0.85)$ \\
\hline Acceptance of evolution & $3.93(0.82)$ \\
\hline I believe that animals have changed over time by a process of evolution & $4.26(0.87)$ \\
\hline I accept evolution by natural selection as a well-supported scientific theory & $4.10(0.97)$ \\
\hline I believe that all species, including humans, have a common evolutionary origin & $3.86(1.14)$ \\
\hline I believe that species were created individually and do not change over time ${ }^{a}$ & $1.68(0.86)$ \\
\hline I believe that the theory of evolution by natural selection has many gaps and problems ${ }^{\mathrm{a}}$ & $2.89(1.09)$ \\
\hline Religiosity & $3.06(0.89)$ \\
\hline I believe in God & $3.24(1.41)$ \\
\hline I believe in some kind of afterlife & $3.48(1.20)$ \\
\hline I personally feel a conflict between science and religion & $2.82(1.22)$ \\
\hline I do not think religion can or should make claims about the natural world ${ }^{\mathrm{a}}$ & $3.00(1.19)$ \\
\hline I do not consider myself a religious person ${ }^{\mathrm{a}}$ & $3.25(1.31)$ \\
\hline
\end{tabular}

The rating scale ranged from 1 to 5 , with 1 indicating strong disagreement and 5 indicating strong agreement.

${ }^{a}$ Indicates items that were reverse-coded to generate the mean for the theme

each set of five items had two with a reverse valence from the rest, so that endorsing the theme would involve a mix of "agree" and "disagree" responses.

In part 6 of the questionnaire, participants were asked to write a few sentences to complete a short story about science (the data from this task are not reported), and in the final part of the questionnaire, participants reported demographic information, including age, sex, and number of science courses taken at the university level (education).

Procedure Participants completed the questionnaire as part of a set of experiments, some of which were related to science and some of which were unrelated. Participants were randomly assigned to a packet with 1 of 12 theme orders and one of two item orders.

\section{Results}

Coding The Likert item data was coded by averaging the responses to the five items corresponding to each theme, with two of the items reverse coded such that the resulting value was high to the extent participants endorsed the theme (see Tables 1 and 2 for mean values). For the core science themes, a higher score indicates better understanding of the nature of science; for the limits of science, a higher score indicates a belief that the scientific method has limits; for attitudes toward science, a higher score indicates a greater personal interest in and positive attitude toward science; for acceptance of evolution, a higher score indicates a greater acceptance of evolution; and for the religion theme, a higher score indicates greater religiosity and a greater perceived conflict between science and religion. For initial analyses, the 12 core science themes were further averaged to create an overall measure of participants' understanding of the nature of science (NOS score).

Relationship Between NOS Score, Evolution, and Other Science Themes First, we note that there was a significant correlation between NOS score and the number of science courses taken at the college level, education ( $r=0.27, p<$ 0.05 ), which provides an indication of validity for the measures employed (see Table 3). To examine the relationship between NOS score and evolution acceptance, we calculated a correlation between these two measures, which 
Table 3 Correlations between overall NOS score and other themes

${ }^{a}$ Correlation significant at the 0.05 level (two-tailed)

${ }^{\mathrm{b}}$ Correlation significant at the 0.01 level (two-tailed)

\begin{tabular}{llllccc}
\hline & NOS score & Limits & Attitudes & Evolution & Religion & Education \\
\hline NOS score & 1 & $0.22^{\mathrm{a}}$ & $0.39^{\mathrm{b}}$ & $0.40^{\mathrm{b}}$ & -0.16 & $0.27^{\mathrm{a}}$ \\
Limits & & 1 & 0.08 & -0.01 & 0.15 & 0.15 \\
Attitudes & & 1 & $0.34^{\mathrm{b}}$ & -0.18 & $0.33^{\mathrm{b}}$ \\
Evolution & & & 1 & $-0.43^{\mathrm{b}}$ & 0.07 \\
Religion & & & & & 1 & -0.12 \\
Education & & & & & 1 \\
\hline
\end{tabular}

was sizeable and statistically significant $(r=0.40, p<0.01)$. However, this correlation need not indicate a direct relationship between understanding NOS and accepting evolution, as it could be that positive values on both are driven by a common cause, such as level of science education or a positive attitude toward science. Thus, a partial correlation between NOS score and evolution acceptance was calculated, controlling for education and attitude. Critically, this correlation remained sizeable and significant $(r=0.31, p<0.01)$. While this could indicate that accepting evolution contributes to understanding NOS or that both are driven by a common cause not examined here, the most plausible interpretation is that understanding the nature of science makes an independent contribution toward accepting evolution.

Relationship Between Specific Science Themes and Evolution At the outset, we noted that understanding certain science themes could be especially relevant for accepting evolution. In particular, we noted the importance of understanding the status of theories and of appreciating that testing empirical hypotheses can involve complex inferences and methods. This suggests that the themes we have labeled as 'theory support,' 'theory limits,' 'testing,' 'non-linearity,' and 'construction' should correlate with accepting evolution.

Because many of the scores for the 12 science themes were highly correlated with each other and to avoid performing 12 independent statistical tests, the 12 themes were reduced to three components via a factor analysis. The analysis was performed in SPSS using principal component analysis as an extraction method and a direct oblimin rotation to improve the interpretability of the components. The resulting pattern matrix is reported in Table 4. Examining the highest loadings suggests that the first component can be characterized as "complexity" and the second as "theories." The third component, which is less interpretable, is what we call "context," as it involves themes related to the comparison of explanations (theoretical context) and society and culture (broader context). The correlations between these components and accepting evolution are reported in Table 5. The complexity and theory components correlated significantly with accepting evolution, even when controlling for attitude and education. This confirms our initial prediction of a relationship between accepting evolution and understanding the nature of scientific confirmation and testing ("complexity"), as well as understanding the nature of scientific theories ("theories").

Relationship Between Science Themes, Evolution, and Religiosity Religiosity was significantly and negatively correlated with acceptance of evolution $(r=-0.43, p<$ 0.01 ) but was not significantly related to other measures (see Table 3). To understand the basis for the relationship between evolution acceptance and religiosity, we examined each evolution and religion item individually. Two items from the religiosity scale, belief in God and belief in an afterlife, accounted for the overwhelming majority of this relationship, which extended to all five of the evolution items. It is interesting to note that items about a perceived conflict between science and religion were not significantly correlated with responses on the evolution items.

\section{Summary and Interpretation of Findings}

We found that among college undergraduates, acceptance of evolution was negatively correlated with religiosity,

Table 4 Pattern matrix for the factor analysis involving science themes

\begin{tabular}{lccr}
\hline & $\begin{array}{l}\text { Component } 1 \\
(35 \%)\end{array}$ & $\begin{array}{l}\text { Component } 2 \\
(11 \%)\end{array}$ & $\begin{array}{l}\text { Component 3 } \\
(9 \%)\end{array}$ \\
\hline Theory support & -0.25 & 0.89 & 0.08 \\
Theory limits & 0.23 & 0.64 & -0.44 \\
Testing & 0.82 & 0.03 & -0.28 \\
Nonlinearity & 0.63 & 0.31 & -0.15 \\
Construction & 0.68 & -0.12 & 0.18 \\
Provisionality & 0.53 & 0.13 & 0.41 \\
Continuity & 0.50 & 0.51 & -0.01 \\
Comparison & 0.02 & 0.15 & 0.62 \\
Creativity & 0.60 & -0.12 & 0.13 \\
Community & 0.22 & 0.53 & 0.29 \\
Applications & 0.00 & 0.58 & 0.22 \\
Society and & 0.33 & 0.18 & 0.49 \\
culture & & & \\
\hline
\end{tabular}


Table 5 The correlation between each component of the nature of science themes and accepting evolution

\begin{tabular}{lcc}
\hline & $\begin{array}{l}\text { Correlation with } \\
\text { evolution }\end{array}$ & $\begin{array}{l}\text { Partial correlation with } \\
\text { evolution }\end{array}$ \\
\hline C1: Complexity & $0.29^{\mathrm{b}}$ & $0.21^{\mathrm{a}}$ \\
C2: Theories & $0.37^{\mathrm{b}}$ & $0.33^{\mathrm{b}}$ \\
C3: Context & 0.13 & 0.01 \\
NOS score & $0.40^{\mathrm{b}}$ & $0.31^{\mathrm{b}}$ \\
\hline
\end{tabular}

The final column reports the partial correlation, controlling for attitudes and education. The first component, "complexity," reflects understanding that science is nonlinear and involves constructing theories on the basis of many sources of evidence. The second component, "theories," reflects understanding that scientific theories are not just guesses but also cannot be definitively proved. Both of these components are significantly correlated with accepting evolution.

${ }^{\text {a }}$ Correlation significant at the 0.05 level (two-tailed)

${ }^{\mathrm{b}}$ Correlation significant at the 0.01 level (two-tailed)

positively correlated with a positive attitude toward science, and positively correlated with understanding the nature of science. Critically, the correlation between accepting evolution and understanding the nature of science remained sizeable and statistically significant even when controlling for the effects of attitude toward science and previous science instruction. Past science education was not significantly correlated with accepting evolution. This finding is in line with previous work that documents a weak relationship between understanding evolution and accepting evolution, as most science courses at the college level focus on specific scientific content and not on the nature of science.

The finding that understanding the nature of science is correlated with accepting evolution suggests that improving students' understanding of the nature of science could causally influence their acceptance of evolution. However, further study will be required to establish this causal interpretation of our correlational findings, as well as to verify that the relationship between understanding the nature of science and accepting evolution holds among students of different ages and backgrounds. We hope the current findings provide impetus for such research.

In the introduction, we presented several reasons for expecting a relationship between understanding the nature of science and accepting evolution. While our current findings support such a relationship, this relationship could arise in multiple ways. One possibility is that understanding the nature of science (and, in particular, the nature of theories and of confirmation) directly impacts one's willingness to accept evolution. A second possibility is that understanding these aspects of the nature of science prevents one from being swayed toward unwarranted skepticism by antievolution messages. Indeed, many antievolution slogans and strategies hinge on the claim that evolution is "only a theory" and question the legitimacy and strength of the enormous body of evidence supporting evolution (Scott 2004).

A tentative reason to endorse the possibility that understanding the nature of science prevents the rejection of evolution rather than directly leading to its acceptance comes from cross-cultural work. Misconceptions about the nature of science and in particular a failure to appreciate the aspects of science related to the factor we identified as "complexity" are fairly robust cross-culturally (Leach et al. 1997; Kang et al. 2004; Huang et al. 2005; Liang et al. 2006; Deniz et al. 2008), while the rejection of evolution is not (Miller et al. 2006). If understanding the nature of science were a prerequisite to accepting evolution, one would expect high acceptance to indicate high understanding. Given that this is not the case, it seems more likely that understanding the nature of science plays a special role in the USA, where antievolution messages are prominent and often leveled against evolution's scientific credentials.

If our characterization of the role of understanding the nature of science in accepting evolution is correct, it has two implications. First, teaching the nature of science is unlikely to lead students who endorse an alternative conception, such as creationism, to reject that alternative (see also Bishop and Anderson 1990; Lawson and Worsnop 1992; Trani 2004). Instead, the greatest influence may be on students who are not committed to creationism but who are unsure about evolution-perhaps as a result of antievolution messages. Second, instruction in the nature of science could be most beneficial at the earliest stages of science instruction. Although serious discussions of the nature of science, if broached at all, are often reserved for high school and beyond, it is critical that children begin to develop an understanding of science to properly evaluate antievolution messages when they are first encountered. There is also some support for the idea that accepting evolution improves students' ability to understand evolution (e.g., McKeachie et al. 2002; Ingram and Nelson 2006), which provides a further reason for students to be exposed to the nature of science and for this instruction to occur early on in science education.

The calls for an increased emphasis on teaching the nature of science both for the sake of evolution education (e.g., Pigliucci 2007) and for its own sake (e.g., Alberts 2008; Cronjie 2008) have come from many corners. New approaches to integrating the nature and process of science across the science curriculum (e.g., http://www.understan dingscience.org) will provide resources to help teachers answer these calls and supplement currently available materials (e.g., NAS 2008a, b). Nevertheless, for much of the education community, putting these resources to work and shifting science content emphases will likely involve some reconceptualization of the nature of science. 
Understanding and Teaching the Nature of Science

How should the nature of science be understood and taught? We have considerably simplified a vast and difficult topic for the purposes of exposition in this paper and for the purposes of assessment in the study we report. But, the status of scientific theories is a subtle issue, and the role of evidence and nature of scientific confirmation are complex. Indeed, these topics are the source of controversy in the philosophy of science, where an enormous literature explores different ways of understanding the structure and confirmation of theories (see Godfrey-Smith 2003, for an accessible review). While the controversies within the philosophy of science do not bear on the scientific legitimacy of the theory of evolution (all approaches recognize the scientific legitimacy of the theory of evolution), they do illustrate that the nature of science is not transparent, with the corollary that it may not be easy for teachers to effectively convey the nature of science to students. Nevertheless, we believe that students should be exposed to contemporary philosophical views about the nature of theories and evidence. Below, we highlight three key characteristics of the nature of science.

Scientific Theories are Trustworthy and Reliable but Still Provisional A common misconception among students and the general public revealed in this and other studies concerns what we might call the provisionality of scientific knowledge. On the one hand, students are taught mature theories and the core aspects of those theories. This leads many to conclude that genuine scientific knowledge has been demonstrated beyond all doubt. On the other hand, in colloquial usage, the term "theory" suggests considerable reason for doubt. In science, however, the term "theory" is used for systematic sets of claims for which considerable evidence has been amassed. For example, we use the term theory when talking about the chemical bond or the germ theory of disease.

Students ought to be taught not just the meaning of the word "theory" but the evidentiary status of central scientific theories such as evolution. They are theories for which a tremendous amount of evidence has been amassed, but like all theories, they are accepted in a provisional way. This does not mean that they are mere conjecture but rather that there are no guarantees in scientific inquiry. Some new discovery tomorrow might upset our most deeply held scientific commitments - be it the discovery of a perpetual motion machine or a preCambrian rabbit. We believe that this dynamic aspect of science is part of its excitement and think that this should be communicated directly to students.

Testing Theories Requires Other Theories A more subtle issue involves the way that modern theories are tested.
Foundational framework theories such as contemporary evolutionary theory, quantum mechanics, and the atomic theory of matter were not confirmed directly by evidence, nor could most conceivable experiments single-handedly show them to be false. These theories were tested by the slow accumulation of evidence and inferences made between these framework theories and more specific hypotheses.

For example, one of the most important lines of evidence for evolutionary theory comes from biogeography, something Darwin devoted considerable attention to in the years between the Beagle voyage and the publication of On the Origin of Species. One component of Darwin's research was careful study of his own and others' observations of the Galapagos fauna. On the voyage itself, Darwin had noted differences between the mockingbirds of different islands. He also recalled that the vice governor of the archipelago had informed him that the tortoises differed among the islands and that he could tell by the shape of the shell the origin of any tortoise. Upon his return to England, consultations with Ornithologist John Gould convinced him of further distributions of traits including the now-famous Galapagos finches (Sulloway 1982, 1984; Browne 1996).

The distribution of these animals through the Galapagos Islands is now taken to be a striking example of and evidence for evolution, but there is no direct connection between geographical distributions of similarities and differences in species and evolutionary theory. Connecting these observations to evolutionary theory ultimately draws on taxonomy, geology, climatology, animal behavior, and, nowadays, molecular genetics. Initially, assumptions about climate conditions or ancestral variation might need to be made, but these theoretical assumptions can be later tested on their own. Scientific testing almost always works like this: To test one theory, one has to deploy many additional theories and hypotheses. Sometimes, these other theories and hypotheses will be more or less settled matters, like the age of the earth. But, other times, they are much more provisionally held, like the baseline mutation rate of the genome.

Although the claim that "testing theories requires other theories" might sound complex, the basic insight can be incorporated into existing science instruction. Students can begin to recognize early that the tests they perform in laboratories and discuss in class all rely on assumptions and that these assumptions, in turn, are subject to on-going scientific testing.

There is Not One Scientific Method, Only Scientific Methods Finally, we should emphasize to students that science has no single method. There is no recipe for formulating and testing hypotheses and theories. Scientists are led to their theories from many paths, including logical extensions from known cases, analogical reasoning from 
similar cases, and de novo theorizing. Practical concerns, experimental failures, and even misunderstandings have fruitfully led to the formulation of hypotheses. Sometimes, data collection precedes clear theoretical ideas. Other times, theories come first, without knowing how they can be tested. Furthermore, occasionally, especially in contemporary science, research is conducted by simulation, often with large uncertainties in the output.

The variety in scientific methods is impossible to capture in a set of easily memorized steps. However, exposing students to a diverse sample of scientific ideas and experiments and explicitly discussing the nature of science can help students move beyond a simple picture of scientific methods. Moreover, recognizing the roles of creativity, innovation, and discovery in science may also make the topic more exciting and attractive for students.

\section{Conclusions}

The picture of scientific inquiry we have sketched is more complex than many standard textbook presentations, but we believe that teaching it is essential. Understanding the nature of science and understanding evolutionary theory are ends in themselves and may be mutually reinforcing. In conjunction, they may additionally foster an acceptance of evolution among students.

Teaching science with the aim of changing students' beliefs about evolution raises difficult questions about the proper role of teachers and science education (e.g., Meadows et al. 2000; McKeachie et al. 2002; Ingram and Nelson 2006). But, applying the insights of evolution to medicine, public policy, environmental issues, and decisions about what to eat and how to live requires not only understanding evolution but accepting it as well. We suggest that if we want our students to understand and accept evolution, a more realistic picture of the nature and process of science is essential.

Acknowledgments The authors wish to acknowledge Michael Ranney and Judy Scotchmoor for relevant discussions and Tom Griffiths and Deena Skolnick Weisberg for comments on earlier drafts, as well as Niles Eldredge and an anonymous reviewer for helpful comments. Anna Thanukos was supported in part by a grant from the National Science Foundation (EAR-0624436) to the UC Museum of Paleontology. All three authors are affiliated with the NSF-funded Understanding Science project: http://www.under standingscience.org.

\section{References}

Alberts B. Editorial: considering science education. Science 2008; 319:1589.
American Academy or the Advancement of Science (AAAS), AAAS resolution: statement on the teaching of evolution; 2006. Available at: http://archives.aaas.org/docs/resolutions.php?doc id=443 (accessed April 14, 2008).

Bishop BA, Anderson CW. Student conceptions of natural selection and its role in evolution. J Res Sci Teach 1990;27:417-25.

Brem SK, Ranney M, Schindel J. Perceived consequences of evolution: college students perceive negative personal and social impact in evolutionary theory. Sci Educ 2003;87:181-206.

Browne J. Charles Darwin: voyaging. Princeton: Princeton University Press; 1996.

Bybee RW. Teaching about evolution: old controversy, new challenges. BioScience 2001;51:309-12.

Carey S, Smith C. On understanding the nature of scientific knowledge. Educ Psychol 1993;3:235-51.

Cronjie R. Letter: going public with the scientific process. Science 2008;319:1483-4.

Dagher ZR, BouJaoude S. Scientific views and religious beliefs of college students: the case of biological evolution. J Res Sci Teach 1997;34:429-45.

Dagher ZR, BouJaoude S. Students' perceptions of the nature of evolutionary theory. Sci Educ 2005;89:378-91.

Demastes SS, Settlage J, Good RJ. Students' conceptions of natural selection and its role in evolution: cases of replication and comparison. J Res Sci Teach 1995;32:535-50.

Deniz H, Donnelly LA, Yilmaz I. Exploring the factors related to acceptance of evolutionary theory among Turkish preservice biology teachers: toward a more informative conceptual ecology for biological evolution. J Res Sci Educ 2008;45:420-43.

Farber P. Teaching evolution and the nature of science. Am Biol Teach 2003;65:347-54.

Godfrey-Smith P. Theory and reality: an introduction to the philosophy of science. Chicago, IL: University of Chicago Press; 2003.

Gregory TR. Evolution as fact, theory, and path. Evo Edu Outreach 2008; $1: 46-52$.

Huang C, Tsai C, Chang C. An investigation of Taiwanese early adolescents' views about the nature of science. Adolescence 2005;40:645-54.

Ingram EL, Nelson CE. Relationship between achievement and students' acceptance of evolution or creation in an upper-division evolution course. J Res Sci Teach 2006;43:7-24.

Kang S, Scharmann LC, Noh T. Examining students' views on the nature of science: results from Korean 6th, 8th, and 10th graders. Sci Educ 2004;89:314-34.

Kitcher PS. The advancement of science. Oxford, UK: Oxford University Press; 1993.

Kuhn TS. The structure of scientific revolutions. Chicago, IL: University of Chicago Press; 1962.

Lawson AE, Worsnop WA. Learning about evolution and rejecting a belief in special creation: effects of reasoning skill, prior knowledge, prior belief and religious commitment. J Res Sci Teach 1992;29:143-66.

Leach J, Driver R, Millar R, Scott P. A study in progression in learning about "the nature of science": issues of conceptualization and methodology. Int J Sci Educ 1997;19:147-66.

Liang LL, Chen S, Chen X, Kaya ON, Adams AD, Macklin M, Ebenezer J. Student understanding of science and scientific inquiry: revision and further validation of an assessment instrument. In: Annual Conference of the National Association for Research in Science Teaching (NARST), San Francisco, CA; 2006.

Lederman NG. Students' and teachers' conceptions of the nature of science: a review of research. J Res Sci Teach 1992;29: $331-59$.

Lombrozo T, Shtulman A, Weisberg M. The intelligent design controversy: lessons from psychology and education. Trends Cogn Sci 2006;10:56-7. 
McKeachie WJ, Lin Y-G, Strayer J. Creationist vs. evolutionary beliefs: effects on learning biology. Am Biol Teach 2002;64:189-92.

Meadows L, Doster E, Jackson DF. Managing the conflict between evolution and religion. Am Biol Teach 2000;62:102-7.

Miller JD, Scott EC, Okamoto S. Public acceptance of evolution. Science 2006;313:765-6.

National Academy of Sciences (NAS). Science, evolution, and creationism. Washington, DC: National Academies; 2008a. Available at: http://www.nap.edu/catalog.php?record_id=11876 (accessed April 14, 2008).

National Academy of Sciences (NAS). Teaching about evolution and the nature of science. Washington, DC: National Academies; 2008b. Available at: http://www.nap.edu/catalog.php?record_id=5787 (accessed April 14, 2008).

National Science Teachers Association (NSTA), Position statement: the nature of science. 2000. Available at: http://www.nsta.org/ about/positions/natureofscience.aspx (accessed April 14, 2008).

Nickels MK, Nelson CE, Beard J. Better biology teaching by emphasizing evolution and the nature of science. Am Biol Teach 1996;59:332-6.

Pigliucci M. The evolution-creation wars: why teaching more science is just not enough. McGill J Educ 2007;42:285-306.

Rudolph JL, Stewart J. Evolution and the nature of science: on the historical discord and its implications for education. J Res Sci Teach 1998;53:1069-89.

Rutledge M, Warden M. Evolutionary theory, the nature of science, and high school biology teachers: critical relationships. Am Biol Teach 2000;62:123-31.
Scharmann LC, Harris WM. Teaching evolution: understanding and applying the nature of science. J Res Sci Teach 1992; 29:375-88.

Scharmann LC, Smith MU, James MC, Jensen M. Explicit reflective nature of science instruction: evolution, intelligent design, and umbrellaology. J Sci Teacher Educ 2005;16:27-41.

Scott EC. Evolution vs. creationism. Westport, CT: Greenwood; 2004.

Shtulman A. Qualitative differences between naive and scientific theories of evolution. Cogn Psychol 2006;52:170-94.

Sinatra GM, Southerland SA, McConaughy F, Demastes JW. Intentions and beliefs in students' understanding and acceptance of biological evolution. J Res Sci Teach 2003;40: $510-28$.

Solomon J, Scott L, Duncan J. Large-scale exploration of pupils' understanding of the nature of science. Sci Educ 1996;80: 493-508.

Sulloway F. Darwin and his finches: the evolution of a legend. J Hist Biol 1982;115:1-53.

Sulloway F. Darwin and the Galapagos. Biol J Linn Soc 1984;21:29-59.

Tattersall I. What's so special about science? Evo Edu Outreach 2008;1:36-40.

Trani R. I won't teach evolution; It's against my religion. And now for the rest of the story.... Am Biol Teach 2004;66:419-27.

Verhey SD. The effect of engaging prior learning on student attitudes toward creationism and evolution. Bioscience 2005;55: 996-1003. 